\title{
Fahrwerk virtuell - \\ 11. chassis.tech plus 2020
}

Die chassis.tech plus, bekannt als Münchner Fahrwerk-Symposium, fand zum ersten Mal nicht in

Bayern, sondern virtuell statt. Die mehr als 200 Teilnehmer konnten sich nach individueller Vorliebe ihr eigenes Programm der vierzügigen Veranstaltung im Internet zusammenstellen. Für lebendige Interaktion der Besucher sorgten die Q\&As und Chatforen.

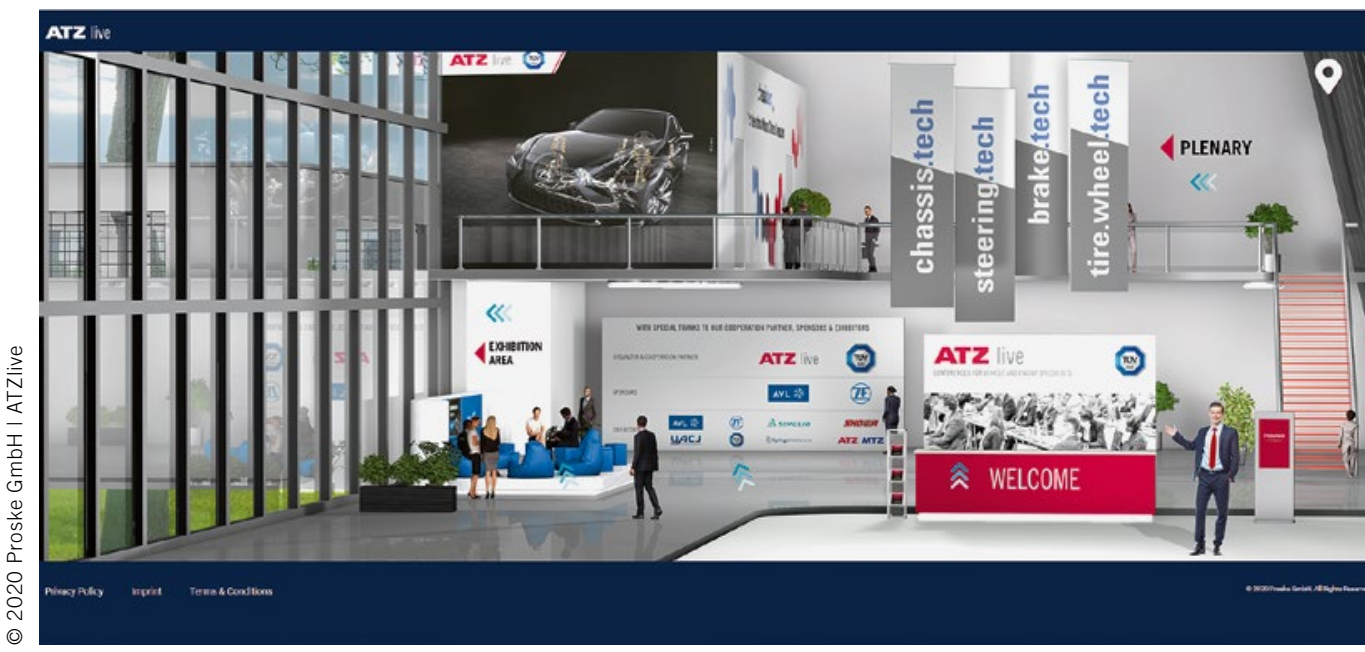

\section{ÜBER 200 TEILNEHMER IM INTERNET}

Das war ein voller Erfolg: Bei der erstmals virtuell ausgerichteten chassis.tech plus 2020 machten über 200 Teilnehmer mit. Durch die Covid-19-Pandemie musste die elfte Auflage (23. und 24. Juni 2020) vom Bayerischen Hof in das World Wide Web verlagert werden. Mit etwas Verspätung und ein paar Ruckelbildern, die bei Videokonferenzen aber gewohnt und üblich sind, starteten die Keynotes und über 42 Vorträge.
Die internationalen Teilnehmer wurden vom Wissenschaftlichen Leiter der Tagung, Prof. Peter E. Pfeffer, Hochschule München, und Dr. Alexander Heintzel, Chefredakteur der ATZMTZ-Gruppe, live im Internet begrüßt. ATZlive und der Partner TÜV Süd veranstalteten die chassis.tech plus wieder gemeinsam. In sieben Keynotes zeigten Schaeffler, Volkswagen, Showa und Toyota sowie Hochschule Kempten, TÜV Süd und Ford R\&A Europe neue Entwicklungen der Fahrwerktechnik auf.

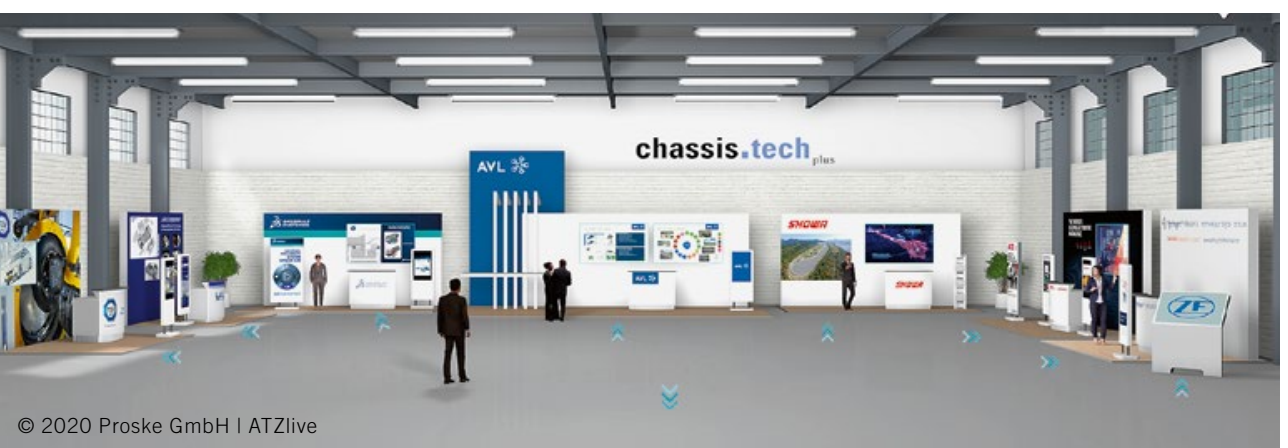

Die Online-Ausstellung mit Ständen von AVL, Dassault Systèmes, Showa, Springer Professional, TÜV Süd und UACJ sowie mit einem Infoelement von ZF bereicherte das virtuelle Event, Teilnehmer konnten sich mit vielen Informationen versorgen

\section{ERFAHRUNGEN MIT BEHINDERTEN- FAHRZEUGEN NUTZEN}

Dr. Keiwan Kashi, Schaeffler Technologies, beschäftigte sich in seiner Plenarrede mit den X-by-Wire-Systemen für Intelligent Connected Vehicles (ICVs). Dazu zählte er People Mover, Robotaxis, urbane Busse und Shuttles, aber auch Lieferwagen für Güter, die alle zukünftig hochautomatisiert nach SAE-Level 4 und 5 durch die Städte bewegt werden. Das aktuelle Hauptproblem bei der ICV-Automatisierung sei 
